\title{
28 Research Square \\ Effectiveness of pelvic packing in hemodynamically unstable patients with pelvic fracture: a meta-analysis
}

\section{Pengyu Li}

Peking University First Hospital

Fanxiao Liu

Shandong Provincial Hospital

Lin Li

Shandong Provincial Hospital

\section{Qinghu Li}

Shandong Provincial Hospital

Dongsheng Zhou

Shandong Provincial Hospital

Jinlei Dong

Shandong Provincial Hospital

Dawei Wang ( $\sim$ sphwangdawei@163.com )

Shandong Provincial Hospital

\section{Research article}

Keywords: Pelvic fracture, Hemodynamic instability, Pelvic packing, Angiography, Meta-analysis, Mortality

Posted Date: July 15th, 2020

DOI: https://doi.org/10.21203/rs.3.rs-42238/v1

License: (c) (i) This work is licensed under a Creative Commons Attribution 4.0 International License. Read Full License 


\section{Abstract \\ Background}

Pelvic packing (PP) has been increasingly used for bleeding control in severe pelvic trauma. However, its effectiveness remains controversial. This meta-analysis was performed systematically to determine the efficiency of PP in pelvic fracture patients with hemodynamic instability.

\section{Methods}

Three databases, PubMed, Embase and Cochrane Library were systematically searched to identify studies presenting comparisons between protocol including PP and protocol without PP. Mortality, transfusion requirement and length of hospitalization were extracted and pooled for meta-analysis. Relative risk (RR) or standard mean difference (SMD) with their confidence interval (CI) was used for the pooled statistical indexes included mortality, transfusion requirement and length of hospitalization.

\section{Results}

Ten studies involving 560 patients were identified eligible for meta-analysis. A significantly reduced overall mortality $(\mathrm{RR}=0.63,95 \% \mathrm{Cl}=0.50$ to $0.79, \mathrm{p}<0.01)$ as well as reduced mortality within $24 \mathrm{~h}$ after admission (RR $=0.42,95 \% \mathrm{Cl}=0.27$ to $0.63, \mathrm{p}<0.01)$ and due to hemorrhage $(\mathrm{RR}=0.27,95 \% \mathrm{Cl}=0.15$ to $0.49, \mathrm{p}<0.01)$ was shown by PP. The usage of PP also decreased the need for pre-operative transfusion (SMD $=-0.44,95 \% \mathrm{Cl}=$ -0.69 to $-0.18, \mathrm{p}=0.001)$ but had no influence on transfusion during the first $24 \mathrm{~h}$ after admission $(\mathrm{SMD}=0.04$, $95 \% \mathrm{Cl}=-0.24$ to $0.31, \mathrm{p}=0.215)$ and length of hospitalization (ICU and total stays).

\section{Conclusions}

This meta-analysis indicates that a treatment protocol including PP significantly reduce mortality and transfusion requirement before intervention in pelvic fracture patients with hemodynamic instability. An algorithm in which pelvic packing is performed as first-line treatment was recommended and complemented with angiography and embolization for patients with traumatic pelvic hemorrhage.

\section{Introduction}

Pelvic fractures are often caused by high energy trauma with high mortality which is always attributable to bleeding [1, 2]. Hemorrhage is the most common cause of death within the first $24 \mathrm{~h}$ after injury [3] and the reported mortality rate of patients with hemodynamic instability due to severe pelvic fracture is as high as $40 \%$ [4]. Therefore, early recognition and control of the hemorrhage is vital. Multidisciplinary approaches have been used in managing bleeding including operative managements such as external fixation and pelvic packing (PP), endovascular interventions like angioembolization and resuscitative endovascular balloon occlusion of the aorta (REBOA). Among them, angioembolization and PP are most widely used and of greatest concern. 
Angiography and embolization, first discussed in 1972, were reported to have a success rate ranging from $80-$ $100 \%$ for arterial hemorrhage $[4,5]$ but had little effectiveness in controlling venous bleeding [6]. However, arterial bleeding only accounts for $10-15 \%$ of cases and in more than $80 \%$ of patients, the hemorrhage originates from injured veins or fractured pelvic fragments $[7,8]$. Furthermore, the preparation for angiography suite and specialized interventional radiologist is time-consuming and delays have been associated with an increase in mortality [9].

Pelvic packing was originally described in Germany in 1994 by directly addressing the hemorrhage from retroperitoneal space $[10,11]$. It is a quick and effective procedure which is most commonly used for venous bleeding. PP can be performed within 20 minutes in emergency room by experienced surgeons [12].

Institutions from different countries have applied PP as part of the treatment algorithm for hemodynamically unstable patients in the 20th century, the results have showed that PP was as effective as AE and patients may benefit from the change of protocol for it showed a reduction of mortality and blood transfusion $[6,11-18]$. We performed a quasi-randomized control study in 2014 and our results showed that, compared with angioembolization, pelvic packing had shorter time to intervention and surgical time [3]. However, most studies were just descriptive researches with small to medium cohorts and results varied from different studies so the efficiency of PP remains controversial. Although two meta-analyses regarding PP were found from our search of current literature, one study only included 3 literatures comparing PP with angioembolization [19] and the other was a network meta-analysis with a different aim [20]. We believe a quantitative analysis including large scale of patients would provide more convincing evidences for clinical instruction. The aim of this meta-analysis is to examine the efficacy of early PP in patients with hemodynamic instability due to pelvic fracture. This study hypothesizes that the introduction of PP in the management protocol has a benefit for clinical outcomes that it lowers mortality and transfusion requirement.

\section{Methods}

This meta-analysis was performed in strict accordance with the Preferred Reporting Items for Systematic Reviews and Meta-Analyses (PRISMA) Statement/Guideline [21].

\section{Design and search strategy}

The search process was performed by two investigators, blindly and independently using three databases, PubMed, Embase and Cochrane Library on March 10, 2020 with no language limitations. The complete search terms were: "pelvic packing [All Fields]" AND "pelvic injury [All Fields]" OR "pelvic trauma [All Fields]" OR "pelvic fracture [All Fields]". Additional eligible studies which were neglected by electronic database searching were retrieved by screening reference lists. Overall mortality was determined as primary outcome. Transfusion requirement and length of hospitalization were secondary outcomes.

\section{Inclusion and exclusion criteria}

Included studies had to fulfill all following criteria: a) enrolled patients with pelvic fracture and hemodynamic instability; b) studies comparing clinical outcomes between patients treated with PP and patients without PP or studies presenting a comparison of results between treatment protocol including PP and protocol without PP; and c) articles written in English. 
Exclusion criteria were: a) non-original studies including reviews, meta-analyses, case reports, comments, editorials, letters, correspondences and conference addresses; b) enrolled patients < 14 years old; and c) studies with insufficient data.

\section{Data extraction}

The following data were extracted from included studies: first author's surname, publication year, country of origin, basic characteristics of the participants (numbers, age and gender), study design, injury severity score (ISS), primary and secondary outcomes. All data were independently extracted from eligible publications by two of the authors and any discrepancies were consulted with an experienced orthopedic surgeon until a consensus was achieved.

\section{Quality assessment}

Quality assessment was performed using Newcastle-Ottawa scale (NOS) [22]. The assessment was performed by two authors and disagreements were resolved through discussion between the two assessing authors. We considered a study with a score $>7$ to be at low-risk of bias [22].

\section{Statistical analysis}

Statistical analysis and production of forest plots were performed by Stata 12.0 (StataCorp, College Station, TX, USA). Heterogeneity was assessed using $\mathrm{Chi}^{2}$ test and $\mathrm{l}^{2}$ test. If $\mathrm{p}>0.1$ and $\mathrm{I}^{2}<50 \%$, the heterogeneity was considered insignificant and a fixed effects model was used. Otherwise a random effects model was used. Relative risk (RR) with 95\% confidence interval (CI) was pooled for dichotomous variables and standardized mean difference (SMD) with $95 \% \mathrm{Cl}$ was pooled for continuous variables. To evaluate the stability of results, subgroup analysis according to different factors, publication bias (performed using funnel plot) and sensitivity analysis (conducted by omitting studies one by one) were implemented. A two-tailed $p$ value $<0.05$ indicated statistically significant.

\section{Results}

\section{Search results and study inclusion}

A total of 447 records were retrieved from the three databases after the initial searching. Another 4 records were identified by reviewing citations in the reference. Of the total retrieved studies, 172 were removed because of duplication. Subsequently, 260 articles were excluded after reading titles and abstracts. Then 19 studies were downloaded and assessed for eligibility by reading full texts. Eventually, 10 articles [3, 6, 11, 12, 14-18, 23] were considered to be qualified for this meta-analysis. The detailed selection process is depicted in Fig. 1.

\section{Characteristics of included studies and risk of bias}

The basic characteristics of the 10 included studies are summarized in Table 1. All studies were published from 2009 to 2020, including results from Asia [3, 14-18], Europe [11, 12], the Unites States [6] and Australia [23]. The sample sizes of these studies ranged from 24 to 125, and a total of 560 patients were included. Eight articles [6, $11,12,14-18]$ were retrospective cohort studies and two $[3,23]$ were prospective studies. Eight studies [11, 12, $14-18,23]$ had 9 points and two studies $[3,6]$ had 8 points using NOS score. 


\section{Mortality}

All included studies were evaluated for overall mortality. The mortality was $26.30 \%(71 / 270)$ in PP group and $42.41 \%(123 / 290)$ in Non-PP group. Overall mortality was significantly lower in PP group $(\mathrm{RR}=0.63,95 \% \mathrm{Cl}=$ 0.50 to $0.79, p<0.05$ ) (Fig. 2). The $\mathrm{I}^{2}$ statistic was $0 \%$, indicating no heterogeneity among the included studies. No significant publication bias was shown (Fig. 3). Sensitivity analysis was conducted by omitting studies one by one, indicating the results were stable (Fig. 4). Considering that patients from 2 studies $[15,17]$ were just divided according to the time period whether PP was included in treatment protocol and not all patients in PP group received pelvic packing, subgroup analyses were performed. The patients treated with PP or just protocol including PP all had reduced mortality rate $(\mathrm{RR}=0.63,95 \% \mathrm{Cl}=0.47$ to $0.84, \mathrm{p}<0.05 ; \mathrm{RR}=0.63,95 \% \mathrm{Cl}=0.42$ to $0.93, p<0.05$ ). The pooled results from 4 studies and 7 studies showed that PP decreased $24 \mathrm{~h}$ mortality (RR $=0.42,95 \% \mathrm{Cl}=0.27$ to $0.63, \mathrm{p}<0.05)$ and hemorrhagic mortality $(\mathrm{RR}=0.27,95 \% \mathrm{Cl}=0.15$ to $0.49, \mathrm{p}<0.05)$ respectively (Fig. 5). The $\mathrm{I}^{2}$ statistic was $0 \%$ for $24 \mathrm{~h}$ mortality and hemorrhagic mortality, indicating no heterogeneity among the included studies

\section{Transfusion requirement and length of hospitalization}

Blood transfusion was measured by packed red blood cells (PRBC) units. The combined results showed that PP decreased the need for pre-operative transfusion (SMD $=-0.44,95 \% \mathrm{Cl}=-0.69$ to $\left.-0.18, p<0.05 ; I^{2}=0 \%\right)$ but had no influence on transfusion during the first $24 \mathrm{~h}$ after admission $\left(S M D=0.04,95 \% \mathrm{Cl}=-0.24\right.$ to $0.31, \mathrm{p}>0.05 ; \mathrm{I}^{2}$ $=33.0 \%, 95 \% \mathrm{Cl}=0 \%$ to $76.20 \%$ ) (Fig. 6). Total length of hospital stay and length of stay in ICU weren't changed by PP $(S M D=0.18,95 \% \mathrm{Cl}=-0.30$ to $0.66, \mathrm{p}>0.05 ; \mathrm{SMD}=0.14,95 \% \mathrm{Cl}=-0.28$ to $0.56, \mathrm{p}>0.05$, Fig. 7$)$. The $\mathrm{I}^{2}$ statistic was $67.11 \%(95 \% \mathrm{Cl}, 0 \%$ to $90.50 \%)$ for total length of hospital stay and $59.0 \%(95 \% \mathrm{Cl}, 0 \%$ to $86.35 \%)$ for length of stay in ICU. the cause of heterogeneity was not allowed to find due to insufficient data and a random effects model was used.

\section{Discussion}

Pelvic packing was originally performed using a trans-abdominal approach after laparotomy but with poor results, due to that the disruption of intact peritoneum was attempting to affect tamponade of hemorrhage, leading to aggravation of bleeding [4, 14]. The technique had been changed by Pohlemann et al. [10] in 1994 to packing of retroperitoneum and then modified to ensure direct packing of the pelvic space through a preperitoneal approach [24]. The method is usually performed by making an infra-umbilical midline incision of about $6-8 \mathrm{~cm}$. Skin, subcutaneous tissue and fascia are dissected without violating the peritoneal cavity. Three laparotomy pads are placed below the pelvic brim toward the iliac vessels on each side of bladder [25]. The revision of PP should be done within 48-72 h [26].

After the modification in 1994, PP has been widely used in European trauma centers as a salvage procedure in the management for hemodynamically unstable patients with pelvic fractures [11, 12, 27-29]. Frassini et al. described PP as a life-saving procedure which could be the first step of a multidisciplinary management of pelvic ring disruptions [12]. In the First Italian Consensus Conference, statement agreed the effectiveness of PP and proposed an algorithm in which PP was prior to angiography [30]. Aside from Europe, in the last decade, scholars from China and South Korea reported improved clinical outcomes since adopting PP in the in the initial treatment protocol $[11,15,17,18]$. World Society of Emergency Surgery (WSES) guidelines in 2017, recommend 
that PP should always be considered for patients with pelvic fracture-related hemodynamic instability and maximized effectiveness could be achieved when combined with external fixation [26].

However, surgeons in North America seem to be more in favor of angiography and embolization [31]. In guidelines from both Eastern Association for the Surgery of Trauma (EAST) and Western Trauma Association in the Unites States, angiography remains the mainstay of therapy [32-34]. A multicenter, observational study conducted through the American Association for the Surgery of Trauma (AAST) in 2015, enrolling patients from 11 Level I trauma centers, demonstrated that angioembolization and external fixator placement were the most common method for pelvic hemorrhage [35]. The mortality rate was $32 \%$ in AAST series of pelvic fracture patients in shock [35]. Another modern series in the US revealed that the mortality rate was $27.8 \%$ in patients with hemorrhagic instability and undergoing angiography [31]. Yet in 2016, Burlew et al. in Denver, USA, reported a mortality rate of $21 \%$ in an 11-year single-center study with a modified protocol which considered PP as the first intervention for pelvic fracture hemorrhage [36]. Burlew's group had been continuing sharing their results since adopting PP in treatment protocol in 2004 [13, 24, 36]. Their long-term observational study confirmed that PP reduces mortality compared with other series favoring angiography and embolization, recommending that PP should be used for pelvic fracture patients with unstable hemodynamics [36]. The updated algorithm by Western Trauma Association in 2016 also attached more importance to the use of PP [33].

Pelvic packing has the advantage of lowered mortality and reduced time to intervention $[15,17,18,36]$, but results varied in different researches $[3,6,14]$. Its role in the management of pelvic hemorrhage remains controversial and needs more studies with feasible comparison like angiography. This article includes all current comparative studies and to our knowledge, containing the largest number of patients. Only four of the included studies demonstrated that the implementation of PP in management protocol significantly improved survival $[11,12,15,17]$. The previous relatively small cohorts may lead to results with low credibility. Death within the first $24 \mathrm{~h}$ after admission is commonly due to exsanguination, whereas, mortality after $24 \mathrm{~h}$ is usually from multiple organ failure [10,37]. Different groups showed that the improvement through PP in mortality within $24 \mathrm{~h}$ or due to hemorrhage might be more marked than the improvement in overall mortality $[11,12,15,17]$. Our quantitative synthesis confirmed this finding and we believe the early use of PP is a life-saving procedure in management for patients in hemorrhagic shock.

Delay in hemostatic procedures is associated with increased mortality in patients with pelvic hemorrhage [12]. Every 3 minutes of delay in the resuscitation room leads to a $1 \%$ mortality increase in a hemodynamically unstable patient with blunt abdominal trauma in the first 90 minutes [38]. Early hemostasis should be done as soon as possible.

Currently, angiography is still considered the first choice of hemorrhage control in most institutional algorithms [23]. However, the time required for transportation of patients, preparation of angiography suite and mobilization of trained interventional radiologists is excessive. In contrast, PP can be quickly accomplished either in operation or emergency room $[11,12]$. Osborn et al. reported a mean time to PP of 44 minutes from the emergency department (ED) admission, compared to a mean of 130 minutes to the angiography suite [6]. Average time to operative packing reported from Tai et al. was 79 minutes compared with 140 minutes to angiography [14]. Similar results were shown by Jang et al, with time to intervention in PP group was 55 minutes compared to 194 minutes in Non-PP group [16]. Our previous results also reported that PP had shorter procedure duration than angiography [3]. Recently, a study from Italy demonstrated that the total hemostatic 
procedure time was sharply reduced for patients in PP group, with a mean time of 49 minutes compared to 156 minutes in the No-PP group [12]. Considering lots of studies have confirmed that PP has the advantage of immediacy and rapidity $[3,6,12,14,16,17,23,36]$, we didn't perform a quantitative analysis for that.

Except for consuming time, the availability of angiography varies in hospitals. Low-level trauma centers, especially in remote or rural region, may be not equipped with qualified angiography suite. Meanwhile, interventional radiologists are not in-house at all times [3], and interventions are easily to be delayed during nights and weekends [39]. Metcalfe et al. reported that a $24 \mathrm{~h}$ formal interventional radiology service was only available at $18 \%$ of hospitals in Wales, UK [40]. PP is a fast and easy procedure with a low demand for equipment and short learning curve, deserving a more widespread use. Moreover, the high energy trauma causing pelvic fractures often lead to increased risk of associated injuries. Additionally, three or more procedures are required to address these injuries [36]. The rapid arrestment of hemorrhage by PP facilitates other emergent operative procedures to stabilize polytrauma patients [15].

Pathophysiologically, PRBCs may induce the adverse inflammatory responses by activating inflammatory genes in circulating leukocytes [41]. Wong et al. reported an increased mortality rate by $62 \%$ for every one PRBC unit per hour increase of transfusion rate [42]. Since the need of transfusion is associated with increased ICU length of stay, multiple organ failure and mortality, reducing transfusion is a compelling objective [13]. With PP included in protocol, though the total number of transfusions required in the first $24 \mathrm{~h}$ after admission wasn't changed, the need of transfusion in ED was significantly reduced. We think the reduced time to intervention for PP is critical to the decreased need of pre-operative transfusion. Osborn et al. reported that packing significantly decreased blood transfusion over the $24 \mathrm{~h}$ post-intervention period whereas the angiography demonstrated no such change [6]. Burlew's group also reported a significant reduction in transfusion requirement after PP [13, 36]. This decrease may be attributed to the concurrent management of associated injuries that could otherwise contribute to continuous bleeding [6]. However, our previous study as well as report from Tai et al. demonstrated post-intervention transfusion was similar in patients treated with PP or angiography [3, 14]. On account of inadequate data, we failed to perform a quantitative analysis. Further studies are needed to determine the role PP plays in blood transfusion requirement.

Though most pelvic hemorrhage originates from veins or fractured bones, a combined injury involving both intra-pelvic veins and arteries is not uncommon [28]. Also high rate of arterial injury was found in patients after PP [23]. Despite that the use of PP improves survival; it cannot completely replace angiography and embolization. During initial resuscitation of pelvic trauma, it is difficult to ascertain the accurate source of bleeding [14] so the optimal procedure may be hard to determine in short time. Since the primary source of pelvic bleeding is injured veins or fractured bone and angiography is time-consuming, PP should be considered as the first-line treatment for pelvic fracture patients with unstable hemodynamics. If patients sustained hemodynamically unstable after PP, arterial bleeding should be suspected and angiography is necessary. A complementary association of pelvic packing and endovascular procedures seems to be the best clinical practice based on guidelines from WSES and Western Trauma Association [12]. Suzuki et al. proposed PP as the primary procedure for patients with unstable hemodynamics, whereas angiography could be the first choice in stabilized patients [43]. Totterman et el. reported high rate of arterial injury observed on angiography after PP and suggested that PP should be supplemented with angiography once sufficient hemodynamic stability had been attained [28]. To some extent, PP could be a time-gaining 'bridge technique' to angiography and 
embolization [12]. It should be pointed out that, based on current evidence, it is unclear whether secondary angiography should be performed on all patients or just on those who still has a manifestation of continuous bleeding after PP.

In recent years, resuscitative endovascular balloon occlusion of the aorta (REBOA) has been proposed as an alternative for temporary bleeding control in hemodynamically unstable trauma patients [26]. REBOA has the advantage of a rapid and effective control of arterial hemorrhage with preservation of cerebral and myocardial perfusion [33]. Its usage in patients with pelvic trauma has been increasing especially in the USA. WSES guidelines and Western Trauma Association suggested that REBOA may act as an effective adjunct in the management of hemodynamically unstable pelvic ring injuries [26,33]. However, the occlusion time is associated with ischemia-reperfusion injury and amputation. Currently, REBOA is mainly considered as a bridge from emergent hemostasis to secondary procedure [12] and more studies of high quality are needed.

This study has both strengths and limitations. The strength lies in the large member of enrolled patients. Several limitations are listed as following. First, only two of the included studies were prospective study and no randomized controlled trial was included. However, a randomized study was not reasonable in light of ethical and practical reasons. Second, there was limited data for accessing transfusion requirement. Third, Propensity Score Matching (PSM) Analysis was used to adjust the differences in the baseline characteristics between the two groups in two studies $[11,12]$ and we only enrolled patients after PSM. The neglected data may likely affect the strength of conclusions.

\section{Conclusions}

This meta-analysis indicates that a treatment protocol including PP significantly reduce mortality and transfusion requirement before intervention in pelvic fracture patients with hemodynamic instability. We recommend an algorithm in which pelvic packing is performed as first-line treatment and complemented with angiography and embolization for patients with traumatic pelvic hemorrhage.

\section{Abbreviations}

PP: Pelvic packing; RR:Relative risk; SMD:standard mean difference; Cl:confidence interval; PRISMA:Preferred Reporting Items for Systematic Reviews and Meta-Analyses; ISS:injury severity score; NOS:Newcastle-Ottawa scale; PRBC:packed red blood cells; WSES:World Society of Emergency Surgery; AAST:American Association for the Surgery of Trauma; EAST:Eastern Association for the Surgery of Trauma; ED:emergency department; REBOA:resuscitative endovascular balloon occlusion of the aorta; PSM:Propensity Score Matching

\section{Declarations}

\section{Ethics approval and consent to participate}

This article does not contain any studies with human participants or animals performed by any of the authors.

\section{Consent for publication}

Not applicable. 
Availability of data and materials

All data analyzed during this study are included in this published article.

\section{Competing interests}

The authors declare that they have no competing interests.

\section{Funding}

The study was supported by the National Natural Science Foundation of China (Dawei Wang, NO.:81972057), Natural Science Foundation of Shandong (Dawei Wang, NO.: ZR2017MH004) and Science and Technology Development Foundation of Jinan (Dawei Wang, NO.: 201704123).

\section{Authors' contributions}

PYL contributed to the idea of this study and drafted the manuscript. PYL and FXL searched literatures and screened them independently. Any disagreement was solved by consulting the senior authors (JLD and DWW). PYL, FXL and LL screened data from the ten articles and make Tables. QHL and DSZ played an important role in analyzing the outcomes. PYL and FXL conducted the data analyses and make graphs. JLD and DWW revised the manuscript. All the authors have read and approved the final manuscript.

\section{Acknowledgements}

No.

\section{References}

1. Balogh Z, King KL, Mackay P, McDougall D, Mackenzie S, Evans JA, et al. The epidemiology of pelvic ring fractures: a population-based study. The Journal of trauma. 2007;63(5):1066-73. discussion 72 - 3.

2. Hauschild O, Strohm PC, Culemann U, Pohlemann T, Suedkamp NP, Koestler W, et al. Mortality in patients with pelvic fractures: results from the German pelvic injury register. The Journal of trauma. 2008;64(2):449-55.

3. Li Q, Dong J, Yang Y, Wang G, Wang Y, Liu P, et al. Retroperitoneal packing or angioembolization for haemorrhage control of pelvic fractures - Quasi-randomized clinical trial of 56 haemodynamically unstable patients with Injury Severity Score $\geq 33$. Injury. 2016;47(2):395-401.

4. White CE, Hsu JR, Holcomb JB. Haemodynamically unstable pelvic fractures. Injury. 2009;40(10):1023-30.

5. Papakostidis C, Giannoudis PV. Pelvic ring injuries with haemodynamic instability: efficacy of pelvic packing, a systematic review. Injury. 2009;40(Suppl 4):53-61.

6. Osborn PM, Smith WR, Moore EE, Cothren CC, Morgan SJ, Williams AE, et al. Direct retroperitoneal pelvic packing versus pelvic angiography: A comparison of two management protocols for haemodynamically unstable pelvic fractures. Injury. 2009;40(1):54-60.

7. Conolly WB, Hedberg EA. Observations on fractures of the pelvis. The Journal of trauma. 1969;9(2):104-11.

8. Huittinen VM, Slatis P. Postmortem angiography and dissection of the hypogastric artery in pelvic fractures. Surgery. 1973;73(3):454-62. 
9. Tesoriero RB, Bruns BR, Narayan M, Dubose J, Guliani SS, Brenner ML, et al. Angiographic embolization for hemorrhage following pelvic fracture: Is it "time" for a paradigm shift? Journal of Trauma Acute Care Surgery. 2017;82(1):18-24.

10. Pohlemann T, Gänsslen A, Bosch U, Tscherne HJTiO. The technique of packing for control of hemorrhage in complex pelvic fractures. 1994;9(4):267-70.

11. Chiara O, di Fratta E, Mariani A, Michaela B, Prestini L, Sammartano F, et al. Efficacy of extra-peritoneal pelvic packing in hemodynamically unstable pelvic fractures, a Propensity Score Analysis. World journal of emergency surgery: WJES. 2016;11:22.

12. Frassini SS, Gupta SS, Granieri SS, Cimbanassi SS, Sammartano FF, Scalea TM, et al. EXTRA-PERITONEAL PACKING IN UNSTABLE BLUNT PELVIC TRAUMA: A SINGLE-CENTER STUDY. The journal of trauma and acute care surgery. 2020.

13. Cothren CC, Osborn PM, Moore EE, Morgan SJ, Johnson JL, Smith WR. Preperitonal pelvic packing for hemodynamically unstable pelvic fractures: a paradigm shift. The Journal of trauma. 2007;62(4):834-9; discussion 9-42.

14. Tai DK, Li WH, Lee KY, Cheng M, Lee KB, Tang LF, et al. Retroperitoneal pelvic packing in the management of hemodynamically unstable pelvic fractures: a level I trauma center experience. The Journal of trauma. 2011;71(4):E79-86.

15. Cheng M, Cheung MT, Lee KY, Lee KB, Chan SC, Wu AC, et al. Improvement in institutional protocols leads to decreased mortality in patients with haemodynamically unstable pelvic fractures. Emerg Med J. 2015;32(3):214-20.

16. Jang JY, Shim H, Jung PY, Kim S, Bae KS. Preperitoneal pelvic packing in patients with hemodynamic instability due to severe pelvic fracture: early experience in a Korean trauma center. Scand J Trauma Resusc Emerg Med. 2016;24:3.

17. Lee MA, Yu B, Lee J, Park JJ, Lee GJ, Choi KK, et al. Effects of the establishment of a trauma center and a new protocol on patients with hemodynamically unstable pelvic fractures at a single institution in Korea. European journal of trauma emergency surgery: official publication of the European Trauma Society. 2019;45(2):273-9.

18. Shim H, Jang JY, Kim JW, Ryu H, Jung PY, Kim S, et al. Effectiveness and postoperative wound infection of preperitoneal pelvic packing in patients with hemodynamic instability caused by pelvic fracture. PloS one. 2018;13(11):e0206991.

19. Tang J, Shi Z, Hu J, Wu H, Yang C, Le G, et al. Optimal sequence of surgical procedures for hemodynamically unstable patients with pelvic fracture: A network meta-analysis. Am J Emerg Med. 2019;37(4):571-8.

20. Muntasar AE, Toner E, Alkhazaaleh OA, Arumugam D, Shah N, Hajibandeh S, et al. Effect of angioembolisation versus surgical packing on mortality in traumatic pelvic haemorrhage: A systematic review and meta-analysis. World journal of emergency medicine. 2018;9(2):85-92.

21. Liberati A, Altman DG, Tetzlaff J, Mulrow C, Gotzsche PC, loannidis JP, et al. The PRISMA statement for reporting systematic reviews and meta-analyses of studies that evaluate health care interventions: explanation and elaboration. PLoS Med. 2009;6(7):e1000100. 
22. Wells GA SB, O’Connell D, Peterson J, Welch V, Losos M, et al. The Newcastle-Ottawa Scale (NOS) for assessing the quality of nonrandomised studies in meta-analyses. [Available from:

http://www.ohri.ca/programs/clinical_epidemiology/oxford.asp. Accessed 25 November 2012.

23. Hsu JM, Yadev S, Faraj S. Controlling hemorrhage in exsanguinating pelvic fractures: Utility of extraperitoneal pelvic packing as a damage control procedure. Int J Crit IIIn Inj Sci. 2016;6(3):148-52.

24. Burlew CC, Moore EE, Smith WR, Johnson JL, Biffl WL, Barnett CC, et al. Preperitoneal pelvic packing/external fixation with secondary angioembolization: optimal care for life-threatening hemorrhage from unstable pelvic fractures. J Am Coll Surg. 2011;212(4):628-35. discussion 35 - 7.

25. Smith WR, Moore EE, Osborn P, Agudelo JF, Morgan SJ, Parekh AA, et al. Retroperitoneal packing as a resuscitation technique for hemodynamically unstable patients with pelvic fractures: Report of two representative cases and a description of technique. Journal of Trauma - Injury Infection Critical Care. 2005;59(6):1510-4.

26. Coccolini F, Stahel PF, Montori G, Biffl W, Horer TM, Catena F, et al. Pelvic trauma: WSES classification and guidelines. World journal of emergency surgery: WJES. 2017;12:5.

27. Giannoudis PV, Pape HCJI-iJotCotl. Damage control orthopaedics in unstable pelvic ring injuries. 2004;35(7):671-7.

28. Totterman A, Madsen JE, Skaga NO, Roise O. Extraperitoneal pelvic packing: a salvage procedure to control massive traumatic pelvic hemorrhage. The Journal of trauma. 2007;62(4):843-52.

29. Ertel W, Keel M, Eid K, Platz A, Trentz O. Control of severe hemorrhage using C-clamp and pelvic packing in multiply injured patients with pelvic ring disruption. J Orthop Trauma. 2001;15(7):468-74.

30. Magnone S, Coccolini F, Manfredi R, Piazzalunga D, Agazzi R, Arici C, et al. Management of hemodynamically unstable pelvic trauma: results of the first Italian consensus conference (cooperative guidelines of the Italian Society of Surgery, the Italian Association of Hospital Surgeons, the Multi-specialist Italian Society of Young Surgeons, the Italian Society of Emergency Surgery and Trauma, the Italian Society of Anesthesia, Analgesia, Resuscitation and Intensive Care, the Italian Society of Orthopaedics and Traumatology, the Italian Society of Emergency Medicine, the Italian Society of Medical Radiology -Section of Vascular and Interventional Radiology- and the World Society of Emergency Surgery). World journal of emergency surgery: WJES. 2014;9(1):18.

31. Tesoriero RB, Bruns BR, Narayan M, Dubose J, Guliani SS, Brenner ML, et al. Angiographic embolization for hemorrhage following pelvic fracture: Is it "time" for a paradigm shift? The journal of trauma acute care surgery. 2017;82(1):18-26.

32. Davis JW, Moore FA, McIntyre RC, Cocanour CS, Moore EE, West MA. Western Trauma Association Critical Decisions in Trauma: Management of Pelvic Fracture With Hemodynamic Instability. The Journal of Trauma: Injury Infection Critical Care. 2008;65(5):1012-5.

33. Tran TL, Brasel KJ, Karmy-Jones R, Rowell S, Schreiber MA, Shatz DV, et al. Western Trauma Association Critical Decisions in Trauma: Management of pelvic fracture with hemodynamic instability-2016 updates. The journal of trauma acute care surgery. 2016;81(6):1171-4.

34. Cullinane DC, Schiller HJ, Zielinski MD, Bilaniuk JW, Collier BR, Como J, et al. Eastern Association for the Surgery of Trauma practice management guidelines for hemorrhage in pelvic fracture-update and systematic review. The Journal of trauma. 2011;71(6):1850-68. 
35. Costantini TW, Coimbra R, Holcomb JB, Podbielski JM, Catalano R, Blackburn A, et al. Current management of hemorrhage from severe pelvic fractures: Results of an American Association for the Surgery of Trauma multi-institutional trial. The journal of trauma acute care surgery. 2016;80(5):717-23. discussion 23 - 5.

36. Burlew CC, Moore EE, Stahel PF, Geddes AE, Wagenaar AE, Pieracci FM, et al. Preperitoneal pelvic packing reduces mortality in patients with life-threatening hemorrhage due to unstable pelvic fractures. The journal of trauma acute care surgery. 2017;82(2):233-42.

37. Gruen GS, Leit ME, Gruen RJ, Peitzman AB. The acute management of hemodynamically unstable multiple trauma patients with pelvic ring fractures. The Journal of trauma. 1994;36(5):706-11. discussion 11 - 3.

38. Clarke JR, Trooskin SZ, Doshi PJ, Greenwald L, Mode CJ. Time to laparotomy for intra-abdominal bleeding from trauma does affect survival for delays up to 90 minutes. The Journal of trauma. 2002;52(3):420-5.

39. Schwartz DA, Medina M, Cotton BA, Rahbar E, Wade CE, Cohen AM, et al. Are we delivering two standards of care for pelvic trauma? Availability of angioembolization after hours and on weekends increases time to therapeutic intervention. The journal of trauma acute care surgery. 2014;76(1):134-9.

40. Metcalfe AJ, Davies K, Ramesh B, O'Kelly A, Rajagopal R. Haemorrhage control in pelvic fractures-a survey of surgical capabilities. Injury. 2011;42(10):1008-11.

41. Escobar GA, Cheng AM, Moore EE, Johnson JL, Tannahill C, Baker HV, et al. Stored packed red blood cell transfusion up-regulates inflammatory gene expression in circulating leukocytes. Annals of surgery. 2007;246(1):129-34.

42. Wong YC, Wang LJ, Ng CJ, Tseng IC, See LC. Mortality after successful transcatheter arterial embolization in patients with unstable pelvic fractures: rate of blood transfusion as a predictive factor. The Journal of trauma. 2000;49(1):71-5.

43. Suzuki T, Smith WR, Moore EE. Pelvic packing or angiography: competitive or complementary? Injury. 2009;40(4):343-53.

\section{Tables}

Table.1 Main characteristics of the included studies 


\begin{tabular}{|c|c|c|c|c|c|c|c|c|c|c|}
\hline \multirow{2}{*}{$\begin{array}{l}\text { Author } \\
\text { (year) }\end{array}$} & \multirow[t]{2}{*}{ Country } & \multirow[t]{2}{*}{ Study design } & \multicolumn{3}{|c|}{ No. of patients } & \multicolumn{2}{|c|}{ Age (years) } & \multicolumn{2}{|l|}{ ISS } & \multirow[t]{2}{*}{ NOS } \\
\hline & & & Total & PP & $\begin{array}{l}\text { Non- } \\
\text { PP }\end{array}$ & PP & $\begin{array}{l}\text { Non- } \\
\text { PP }\end{array}$ & PP & $\begin{array}{l}\text { Non- } \\
\text { PP }\end{array}$ & \\
\hline $\begin{array}{l}\text { Osborn } \\
\text { (2009) }\end{array}$ & USA & Retrospective & 40 & 20 & 20 & $\begin{array}{l}37.9 \\
\pm \\
18.9\end{array}$ & $\begin{array}{l}39.5 \\
\pm 17.4\end{array}$ & $\begin{array}{l}54.7 \\
\pm \\
12.7\end{array}$ & $\begin{array}{l}45.9 \\
\pm 8.7\end{array}$ & 8 \\
\hline $\begin{array}{l}\text { Tai } \\
(2011)\end{array}$ & China & Retrospective & 24 & 11 & 13 & $\begin{array}{l}51.2 \\
\pm \\
19.0\end{array}$ & $\begin{array}{l}44.8 \\
\pm \\
24.7\end{array}$ & $\begin{array}{l}40.0 \\
\pm \\
12.5\end{array}$ & $\begin{array}{l}42.3 \\
\pm \\
18.8\end{array}$ & 9 \\
\hline $\begin{array}{l}\text { Cheng } \\
\text { (2015) }\end{array}$ & $\begin{array}{l}\text { South } \\
\text { Korea }\end{array}$ & Retrospective & 125 & 49 & 76 & $\begin{array}{l}45.37 \\
\pm \\
21.02\end{array}$ & $\begin{array}{l}46.84 \\
\pm \\
21.43\end{array}$ & $\begin{array}{l}40.10 \\
\pm \\
14.19\end{array}$ & $\begin{array}{l}45.00 \\
\pm \\
15.71\end{array}$ & 9 \\
\hline $\begin{array}{l}\text { Chiara } \\
\text { (2016) }\end{array}$ & Italy & Retrospective & 50 & 25 & 25 & PSM & & PSM & & 9 \\
\hline $\begin{array}{l}\text { Hsu } \\
(2016)\end{array}$ & Australia & Prospective & 24 & 14 & 10 & $\begin{array}{l}49.9 \\
\pm \\
17.5\end{array}$ & $\begin{array}{l}60.3 \\
\pm \\
23.5\end{array}$ & $\begin{array}{l}32.0 \\
\pm 6.7\end{array}$ & $\begin{array}{l}23.8 \\
\pm \\
12.7\end{array}$ & 9 \\
\hline $\begin{array}{l}\text { Jang } \\
\text { (2016) }\end{array}$ & $\begin{array}{l}\text { South } \\
\text { Korea }\end{array}$ & Retrospective & 30 & 14 & 16 & $\begin{array}{l}59.7 \\
\pm \\
15.0\end{array}$ & $\begin{array}{l}60.9 \\
\pm \\
22.1\end{array}$ & $\begin{array}{l}38.8 \\
\pm 8.3\end{array}$ & $\begin{array}{l}32.2 \\
\pm 4.9\end{array}$ & 9 \\
\hline $\begin{array}{l}\mathrm{Li} \\
(2016)\end{array}$ & China & Prospective & 56 & 27 & 29 & $\begin{array}{l}43 \pm \\
13\end{array}$ & $\begin{array}{l}40 \pm \\
9\end{array}$ & $\begin{array}{l}48 \pm \\
6\end{array}$ & $\begin{array}{l}43 \pm \\
7\end{array}$ & 8 \\
\hline $\begin{array}{l}\text { Lee } \\
\text { (2017) }\end{array}$ & $\begin{array}{l}\text { South } \\
\text { Korea }\end{array}$ & Retrospective & 79 & 43 & 36 & $\begin{array}{l}53.2 \\
\pm \\
19.8\end{array}$ & $\begin{array}{l}50.6 \\
\pm 19\end{array}$ & $\begin{array}{l}38.7 \\
\pm \\
12.5\end{array}$ & $\begin{array}{l}37.2 \\
\pm \\
12.3\end{array}$ & 9 \\
\hline $\begin{array}{l}\text { Shim } \\
\text { (2018) }\end{array}$ & $\begin{array}{l}\text { South } \\
\text { Korea }\end{array}$ & Retrospective & 58 & 30 & 28 & $\begin{array}{l}62.5 \\
\pm \\
14.4\end{array}$ & $\begin{array}{l}57.0 \\
\pm \\
22.8\end{array}$ & $\begin{array}{l}38.4 \\
\pm 8.5\end{array}$ & $\begin{array}{l}38.7 \\
\pm 9.2\end{array}$ & 9 \\
\hline $\begin{array}{l}\text { Frassini } \\
(2020)\end{array}$ & Italy & Retrospective & 74 & 37 & 37 & PSM & & PSM & & 9 \\
\hline
\end{tabular}

\section{Figures}




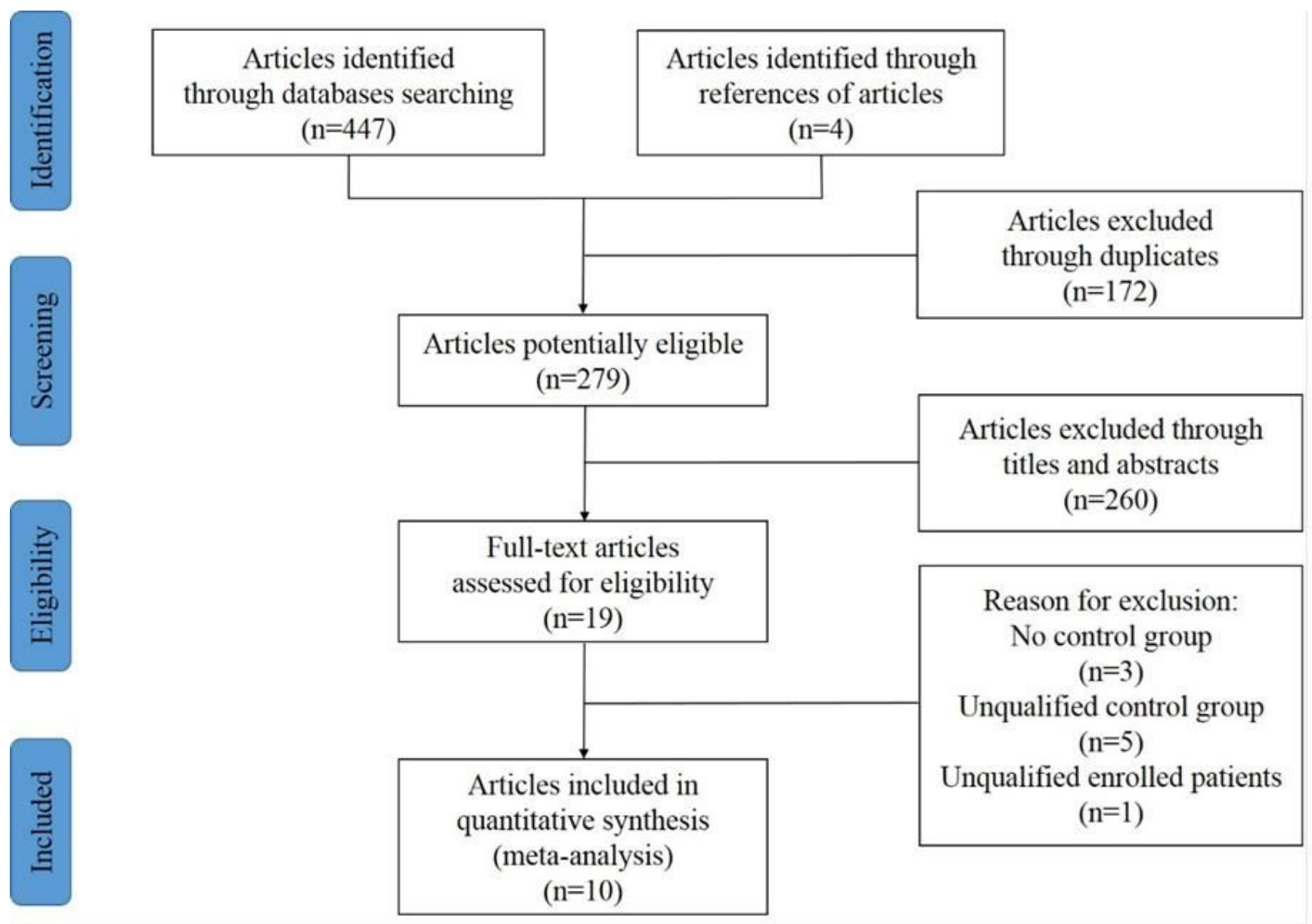

Figure 1

Flow diagram of the selection process for the included studies 


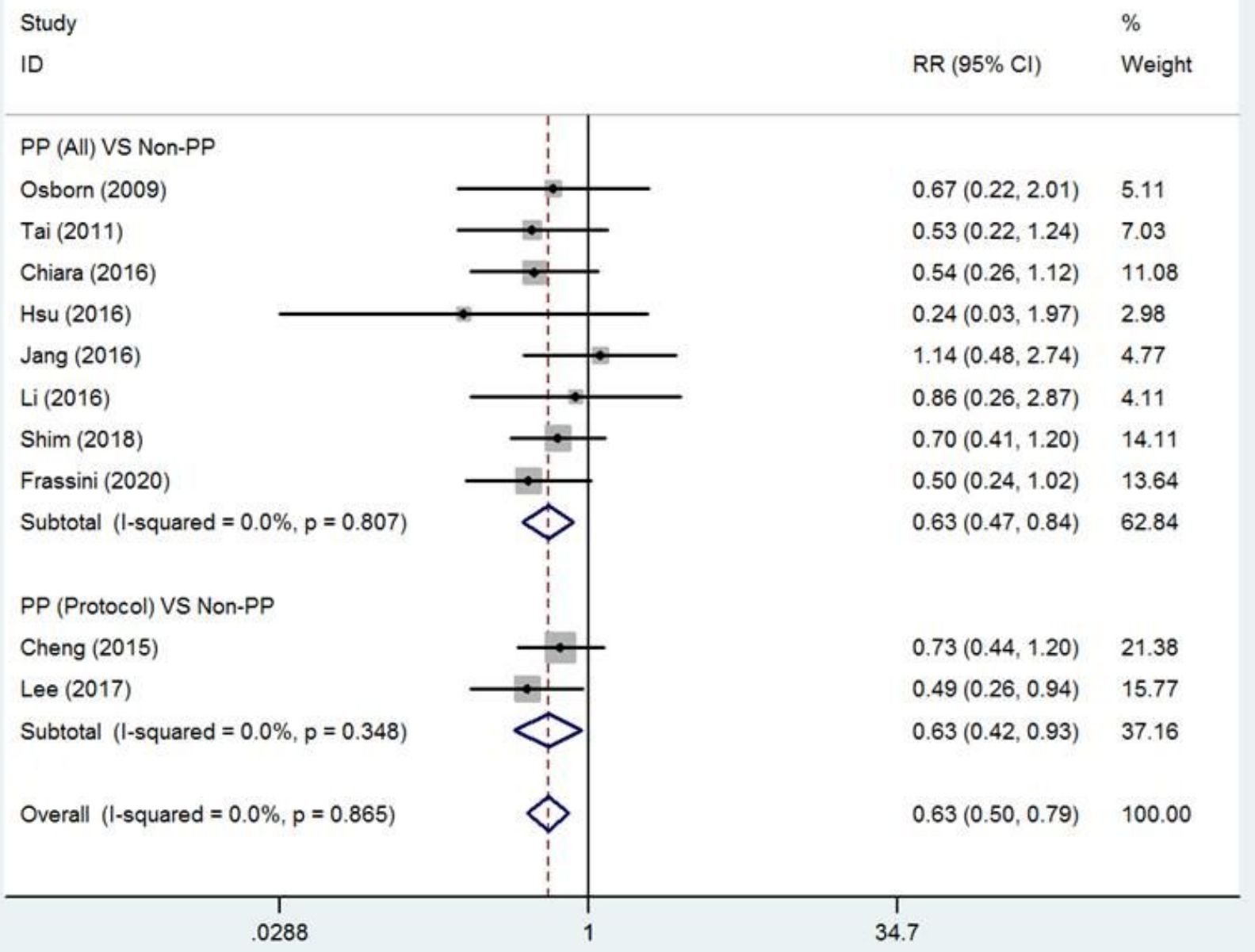

\section{Figure 2}

Forest plot involving comparison of overall mortality. RR, relative risk; $\mathrm{Cl}$, confidence interval 
Funnel plot with pseudo $95 \%$ confidence limits

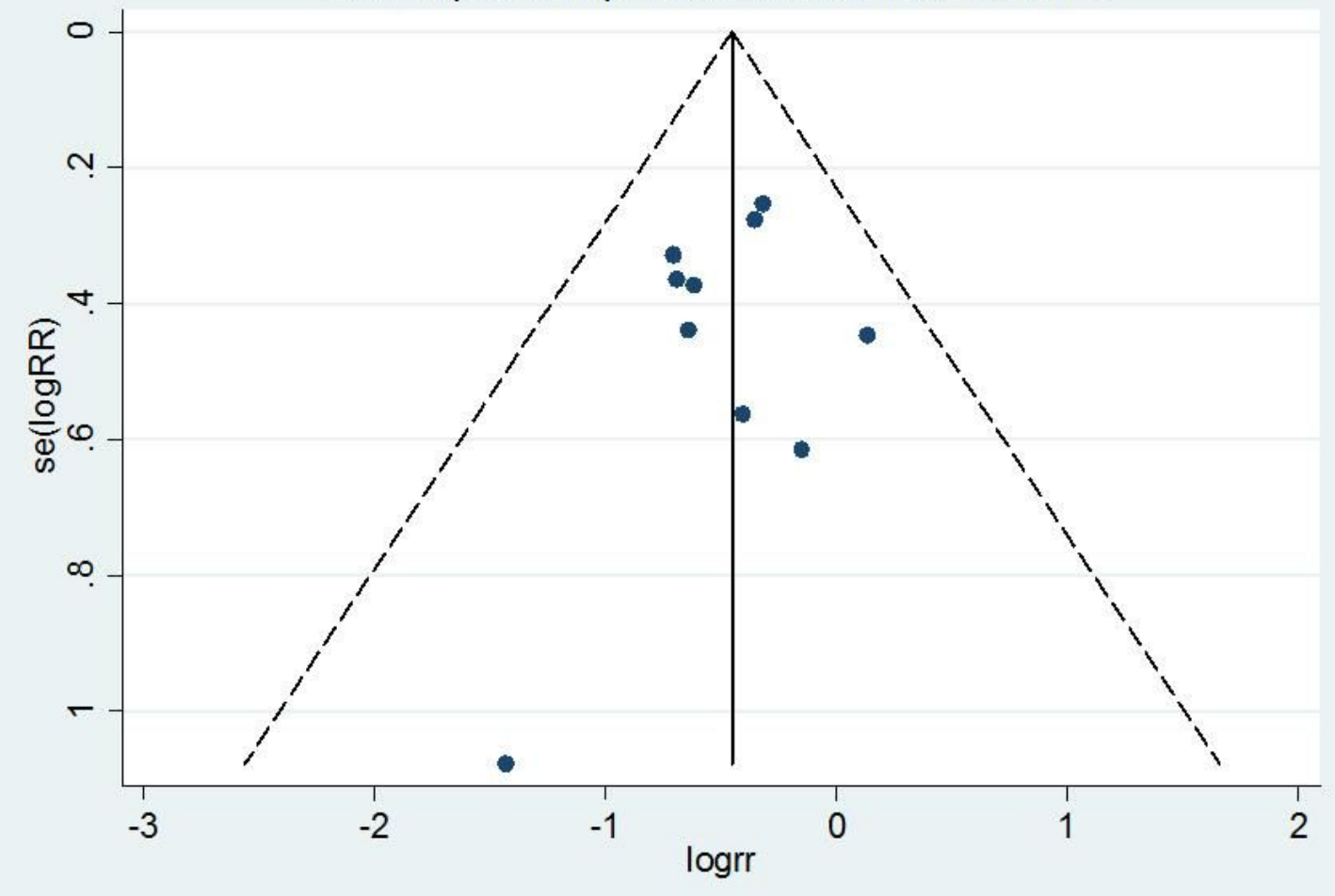

Figure 3

Funnel plot of publication bias. 
Meta-analysis estimates, given named study is omitted

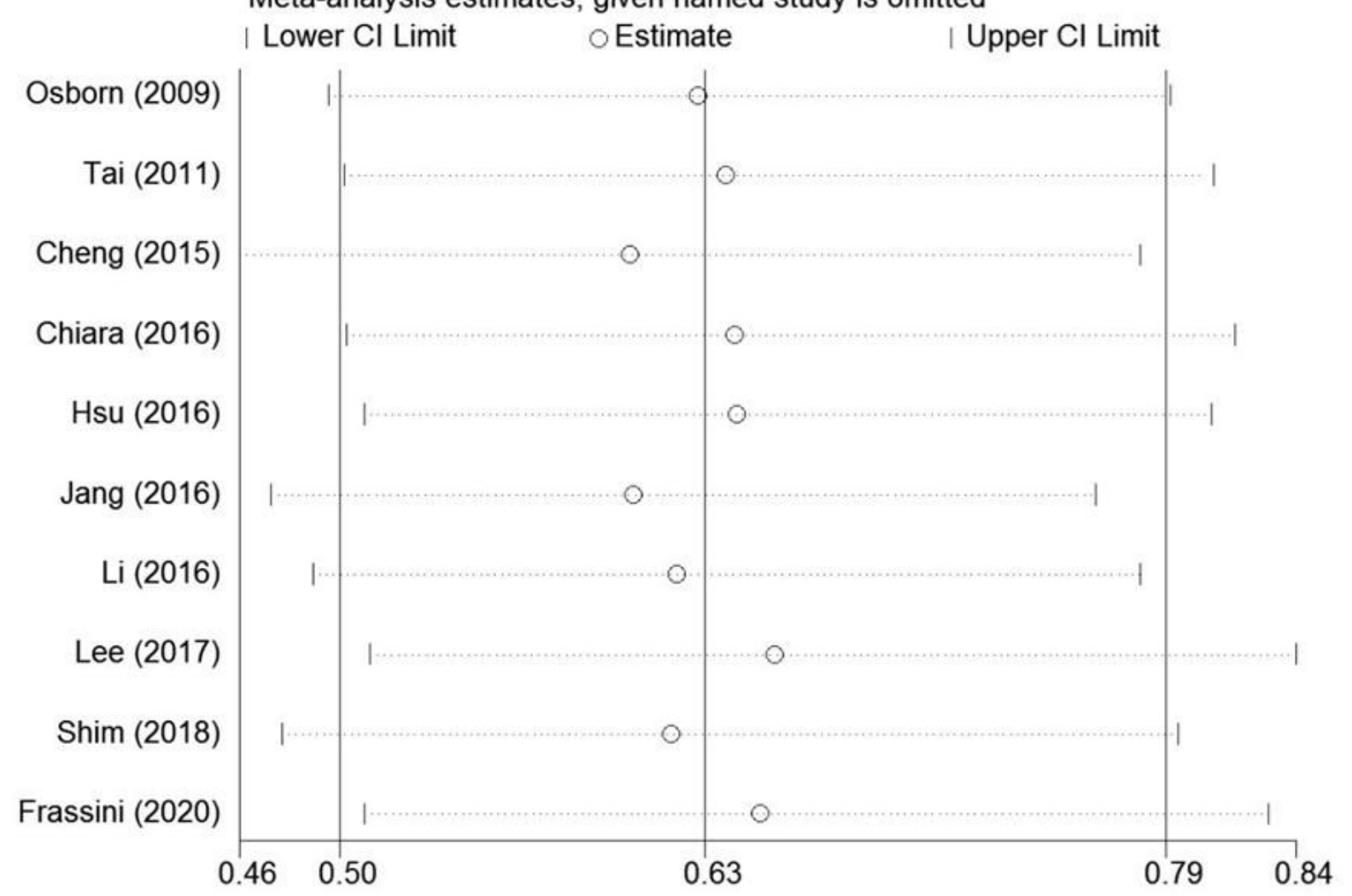

Figure 4

Sensitivity analysis involving overall mortality by omitting studies one by one. 


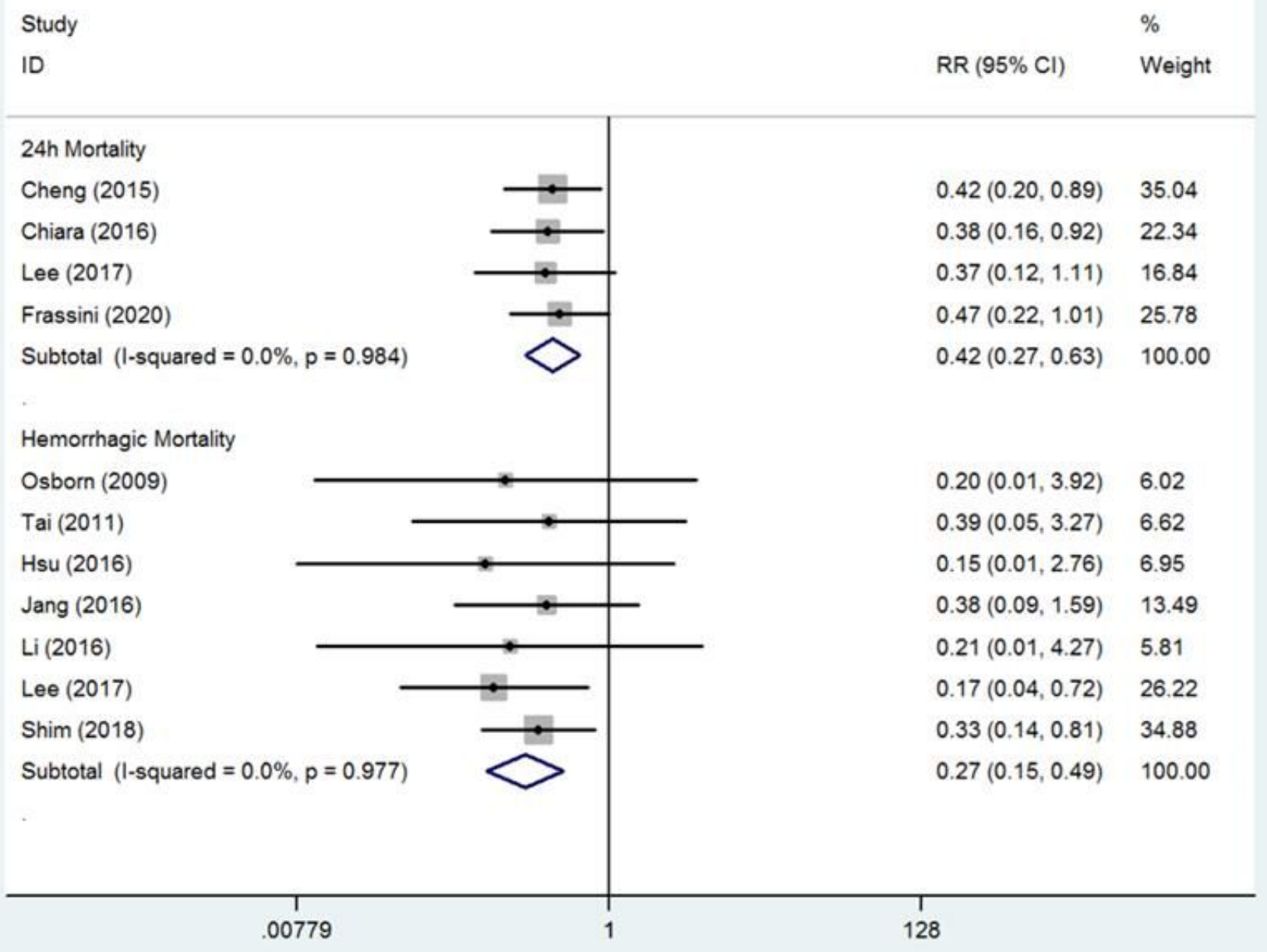

\section{Figure 5}

Forest plot involving comparison of early mortality. RR, relative risk; $\mathrm{Cl}$, confidence interval. 


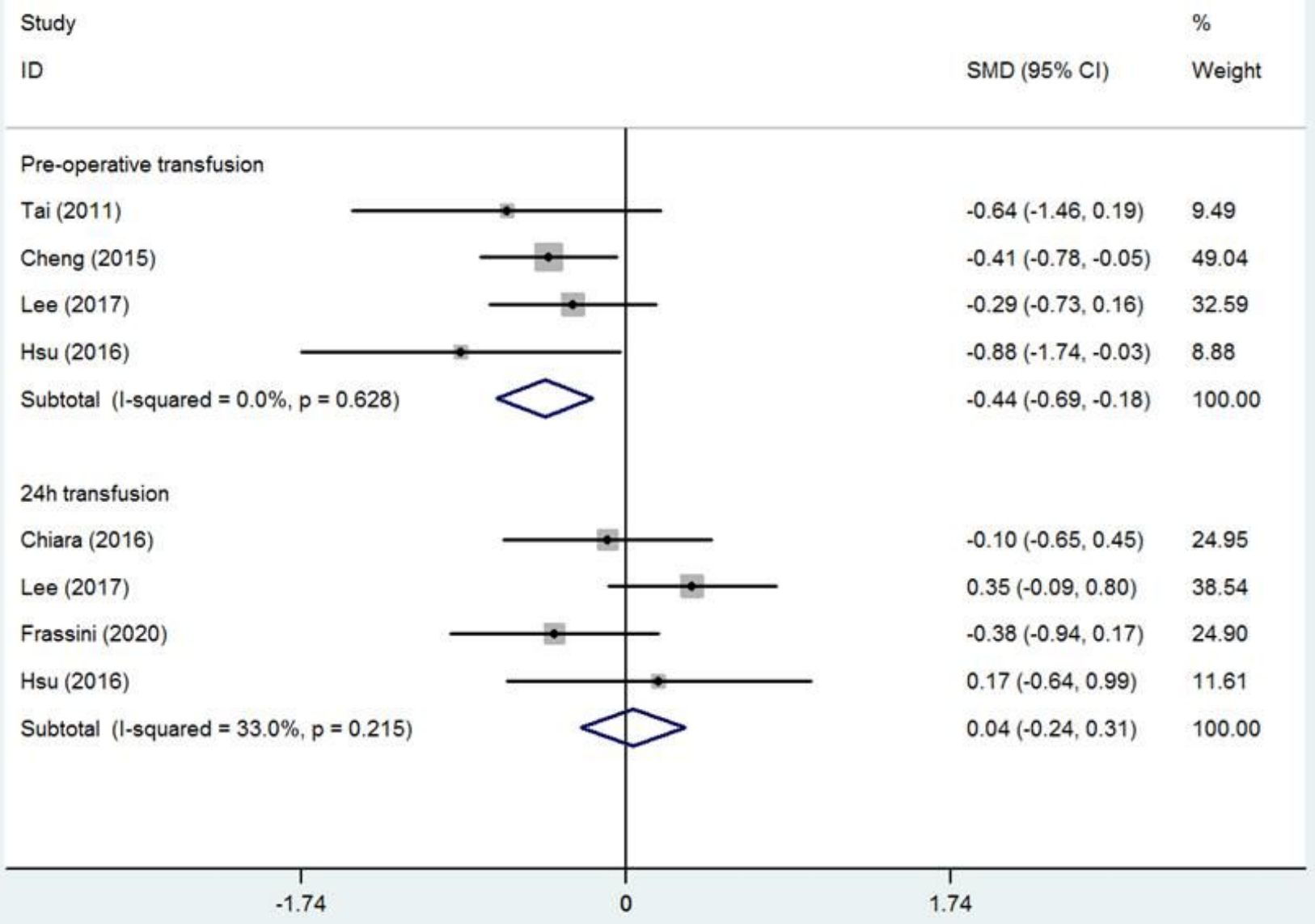

\section{Figure 6}

Forest plot involving comparison of transfusion. SMD, standard mean difference; $\mathrm{Cl}$, confidence interval. 
Study

ID
$\%$

$\operatorname{SMD}(95 \% \mathrm{Cl}) \quad$ Weight

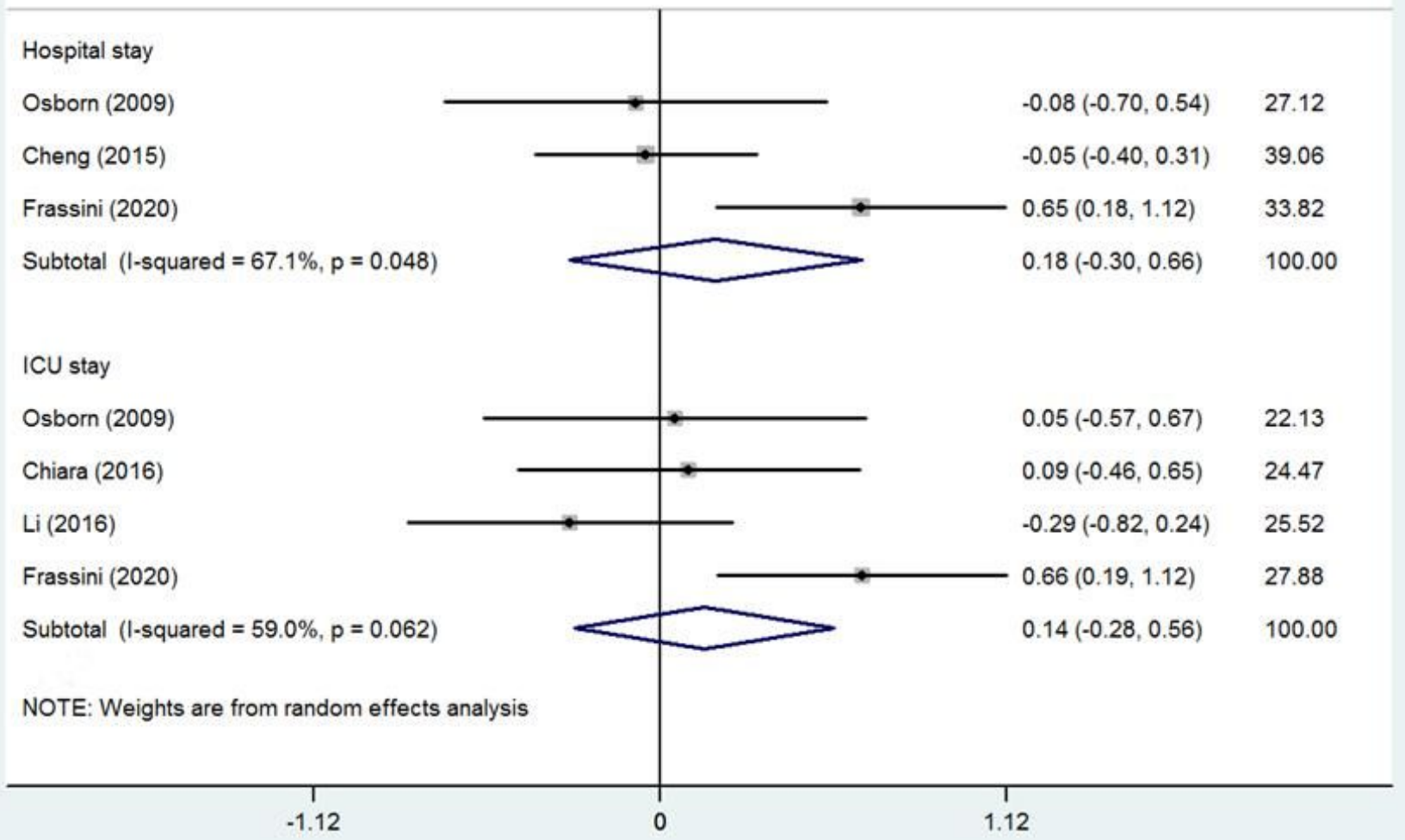

Figure 7

Forest plot involving comparison of length of hospitalization. SMD, standard mean difference; $\mathrm{Cl}$, confidence interval 